\title{
De la cepa a la copa, pasando por la bota. Las rutas de comercialización del vino en el Condado de Huelva
}

\author{
Alba Espina Boa | arquitecta \\ URL de la contribución <www.iaph.es/revistaph/index.php/revistaph/article/view/3643>
}

\section{RESUMEN}

Este artículo desarrolla una parte del trabajo realizado por la autora en 2013 dentro de una estancia de estudios en el Laboratorio del Paisaje del Instituto Andaluz del Patrimonio Histórico, durante la que preparó la documentación necesaria para el diseño de la ruta cultural titulada "Espacios del vino del Condado de Huelva. De la cepa a la copa pasando por la bota", disponible para su consulta en la web del IAPH, que por su extensión no pudo tener cabida en la misma.

La comarca vinícola del Condado coincide, en la actualidad, con áreas de cultivo de vides situadas dentro de los municipios de Palos de la Frontera, Moguer, Niebla, Villarrasa, Bonares, Rociana del Condado, La Palma del Condado, Bollullos Par del Condado, Almonte, Villalba del Alcor, Manzanilla y Chucena. En este territorio, por su topografía, clima y geología, sólo es rentable el cultivo de la uva.

Debido al progresivo colmatamiento de los cauces fluviales que rodean esta comarca, a lo largo de la historia se han buscado nuevas vías comerciales por el Condado para la exportación de su vino: en época romana se usaba la vía Antonino; durante la conquista de América, el carril del Lobo, el puerto de Moguer y el caño de las Siete Suertes; en el s. XIX, los puertos de Huelva y Sevilla y el Tren del Vino del Condado; y ya en la segunda mitad del s. XX, la autovía A92. Todavía en la actualidad, la actividad vitivinícola sigue siendo el principal recurso económico de la comarca.

\section{Palabras clave}

América | Bodegas | Condado de Huelva | Comercio | Cooperativa | Historia | Huelva (Provincia) | Puertos | Transporte marítimo | Transporte terrestre | Trenes | Uvas | Vino | Viticultura | 


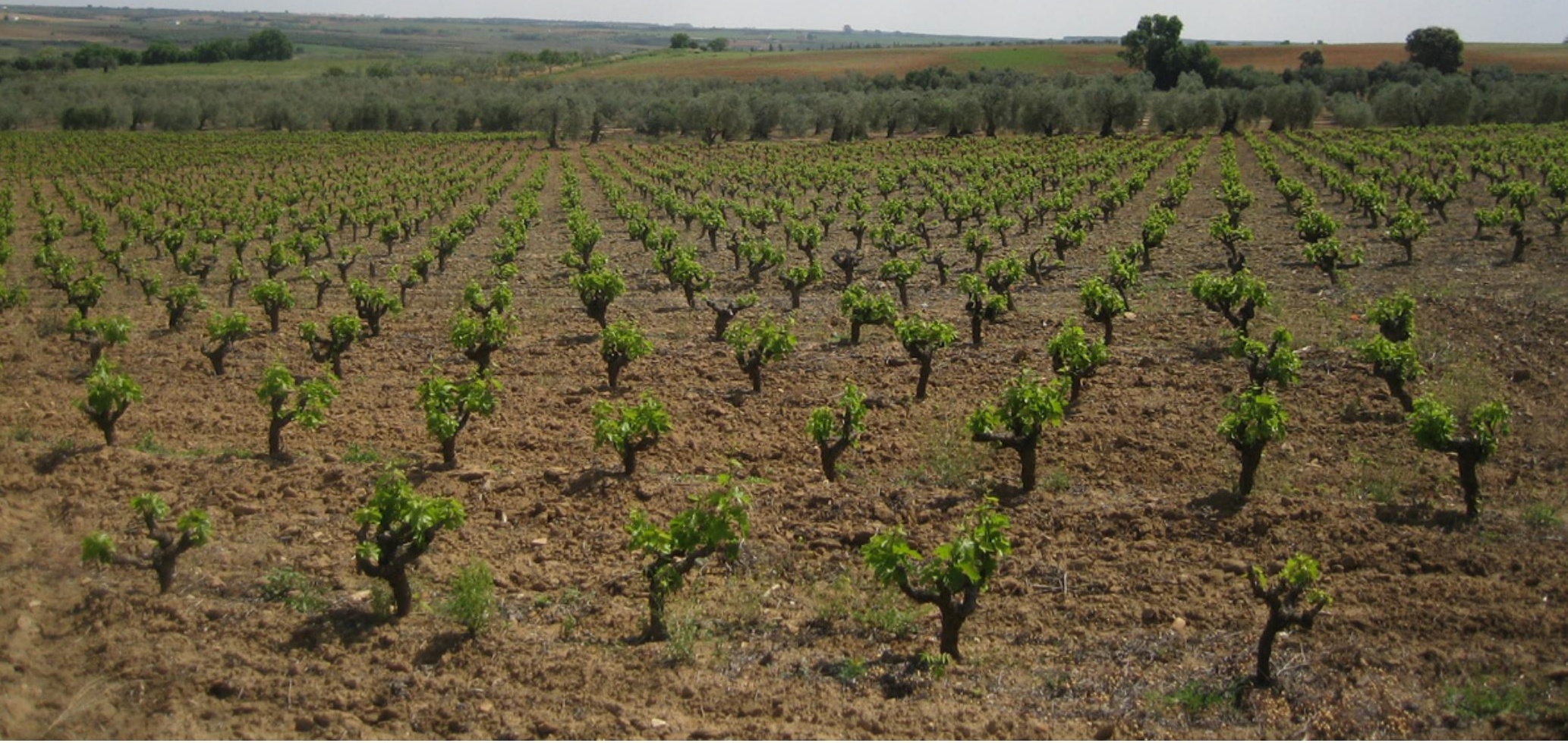

Vides de la variedad zalema. Majuelo de Soto, Bollullos Par del Condado | foto Fondo Gráfico IAPH (Alba Espina Boa) 


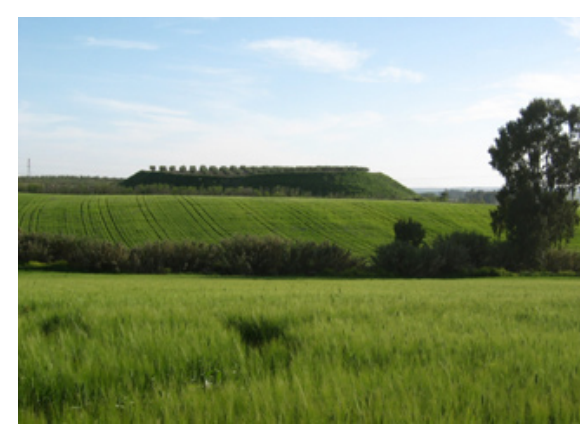

Cerro de las cabezas. Laelia, término de Olivares, Sevilla | foto Urbano López Ruiz

1

Palabras de un viticultor experimentado natural de Bollullos Par del Condado, entrevistado por la autora el 10 de marzo de 2015. La uva zalema es una variedad autóctona del Condado, muy resistente y productiva que, según el Anuario del año 2014 del Consejo del Vino de Condado, continúa ocupando más del 90\% de la producción
La comarca vinícola del Condado coincide, en la actualidad, con áreas de cultivo de vides situadas dentro de los municipios de Palos de la Frontera, Moguer, Niebla, Villarrasa, Bonares, Rociana del Condado, La Palma del Condado, Bollullos Par del Condado, Almonte, Villalba del Alcor, Manzanilla y Chucena. En este territorio, por su topografía, clima y geología, sólo es rentable el cultivo de la uva, y mejor si ésta es zalema ${ }^{1}$. Todavía en la actualidad, la actividad vitivinícola sigue siendo el principal recurso económico de la comarca.

La existencia de vides en el Condado está documentada desde época paleolítica, como se constata por los restos de polen encontrados en la laguna de las Madres (Palos de la Frontera). Sin embargo, debido a que esta zona está dentro del área mundial de distribución de la vid salvaje, estos no demuestran la existencia de una cultura vitivinícola. Como podemos estudiar por fuentes arqueológicas (MATA RUIZ, 1995), el cultivo de la vid, los conocimientos necesarios para la fabricación de vino, su consumo, su producción industrial y su comercio, fueron introducidos en el Condado por los fenicios. En esta época prerromana, aún no se había colmatado la zona de las marismas del Guadalquivir ni de la ría de Huelva, por lo que el Condado se encontraba entre dos rías navegables. Contaba con multitud de puertos comerciales en sus orillas, a los que llegaban las mercancías producidas en el interior.

Siempre según las fuentes arqueológicas consultadas, es ya en época romana cuando se crea la estructura de poblamiento necesaria para poner en plena producción este territorio vinícola. La población se organizaba en una serie de villas o aldeas, que dependían de las ciudades situadas en la vía Antonino: Niebla (Ilipla), Manzanilla (Ostur), Escacena (Itucci) y Olivares (Laelia). Esta vía unía dos puertos importantes, Huelva (Onuba) y Sevilla (Hispalis) (CAMPOS CARRASCO; GÓMEZ TOSCANO, 2001).

La estructura de poblamiento romana se mantiene hasta época musulmana, donde sigue predominando el cultivo de la vid pero, debido a la prohibición religiosa del consumo de vino, las cosechas se dedican en su mayoría a la producción de vinagre y pasas. Tras la expulsión de los moriscos en el s. XIII, el Condado se queda prácticamente despoblado (LAREDO QUESADA, 1992), por lo que desde los nuevos reinos se favorece la llegada de población cristiana. Como en otras regiones vitivinícolas andaluzas, los colonos cristianos son atraídos a estas tierras mediante concesiones de viviendas y de pequeñas parcelas agrícolas, en propiedad y situadas dentro de los ruedos, con la obligación de dedicarlas a la viticultura (BORRERO FERNANDEZ, 1995). De hecho, sigue predominando en la actualidad en esta zona la estructura de poblamiento medieval, el minifundismo y la figura del jornalero-propietario. 
Desde el inicio de la conquista de América hasta el s. XVII, cuando los monjes jesuitas consiguen criar cepas exportadas de Europa y producir vino en sus misiones de Argentina, América es el principal destino de los vinos del Condado (IGLESIAS RODRÍGUEZ, 1995). La enorme demanda de vino de las colonias americanas supone el inicio de la producción masiva para la exportación a gran escala en la comarca y lleva al Condado a buscar de nuevo vías de salida de sus vinos (FOURNEAU, 1975: 65-72). Se hace entonces necesario encontrar nuevos puertos fluviales, ya que los antiguos puertos romanos estaban colmatados y las ciudades con puertos en ese momento (Sevilla) se protegían mediante un sistema medieval de aranceles que encarecían los productos comerciales.

Por esta causa, según F. Fourneau, a finales de s .XVII, la estructura de poblamiento está polarizada hacia tres puertos fluviales:

> El Condado occidental (Palos, Moguer, Lucena, Niebla y Bonares) comercializa su vino a través del puerto de San Juan, en el embarcadero María Suarez, hacia Europa del noroeste.

$>$ El Condado central (Rociana, Almonte, Bollullos, Villarrasa y La Palma) comercializa sus productos a través del carril del Lobo, el cual atraviesa toda la comarca desde La Palma hasta el embarcadero del caño de las Siete Suertes en Aznalcázar, hacia Ámerica a través de Sanlúcar de Barrameda.

$>$ El Condado oriental (Villalba, Manzanilla, Chucena e Hinojos) sigue usando la antigua vía romana para llevar sus vinos hasta el puerto de Sevilla y embarcarlos hacia América. Estas villas eran provincia de Sevilla y podían usar su puerto sin aranceles.

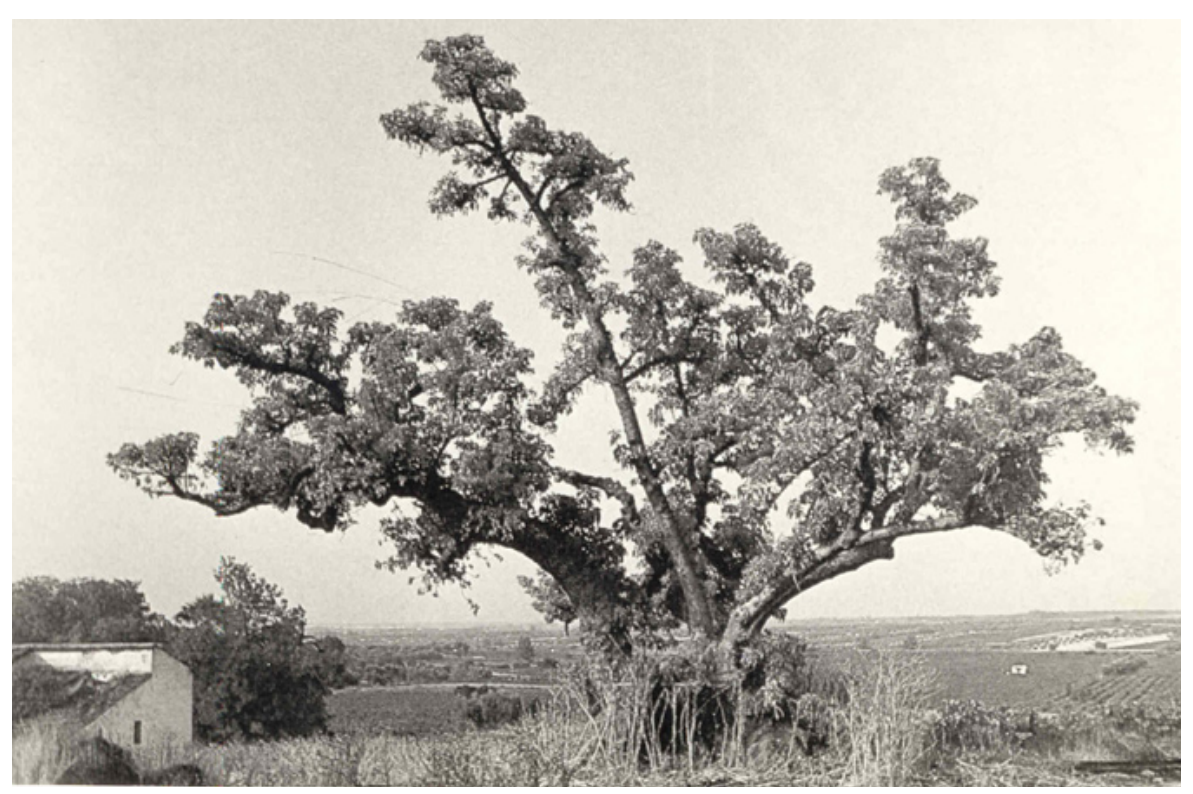

Zápote americano centenario, ya desaparecido, estaba situado en el convento de Morañina en Bollullos Par del Condado | foto Archivo Histórico Municipal, Bollullos Par del Condado 
2

Un vino de pasto es el que es usado como bebida común durante la comida, también se denomina vino de mesa.

3

"Mira, Platero, cómo han puesto el río entre las minas, el mal corazón y el padrastreo. Apenas si su agua roja recoge aquí y allá, esta tarde, entre el fango violeta y amarillo, el sol poniente; y por su cauce casi sólo pueden ir barcas de juguete. ¡Qué pobreza!

Antes, los barcos grandes de los vinateros, laúdes, bergantines, faluchos -El Lobo, La joven Eloísa, el San Cayetano, que era de mi padre y que mandaba el pobre Quintero; La Estrella, de mi tío, que, mandaba Picón-, ponían sobre el cielo de San Juan la confusión alegre de sus mástiles -isus palos mayores, asombro de los niños!-; o iban a Málaga, a Cádiz, a Gibraltar, hundidos de tanta carga de vino... Entre ellos, las lanchas complicaban el oleaje con sus ojos, sus santos y sus nombres pintados de verde, de azul, de blanco, de amarillo, de carmín... Y los pescadores subían al pueblo sardinas, ostiones, anguilas, lenguados, cangrejos... El cobre de Riotinto lo ha envenenado todo. $Y$ menos mal, Platero, que con el asco de los ricos comen los pobres la pesca miserable de hoy... Pero el falucho, el bergantín, el laúd, todos se perdieron.

¡Qué miseria! ¡Ya el Cristo no ve el aguaje alto en las mareas! Sólo queda, leve hilo de sangre de un muerto, mendigo harapiento y seco, la exangüe corriente del río, color de hierro igual que este ocaso rojo sobre el que La Estrella, desarmada, negra y podrida, al cielo la quilla mellada, recorta como una espina de pescado su quemada mole, en donde juegan cual en mi pobre corazón las ansias, los niños de los carabineros".

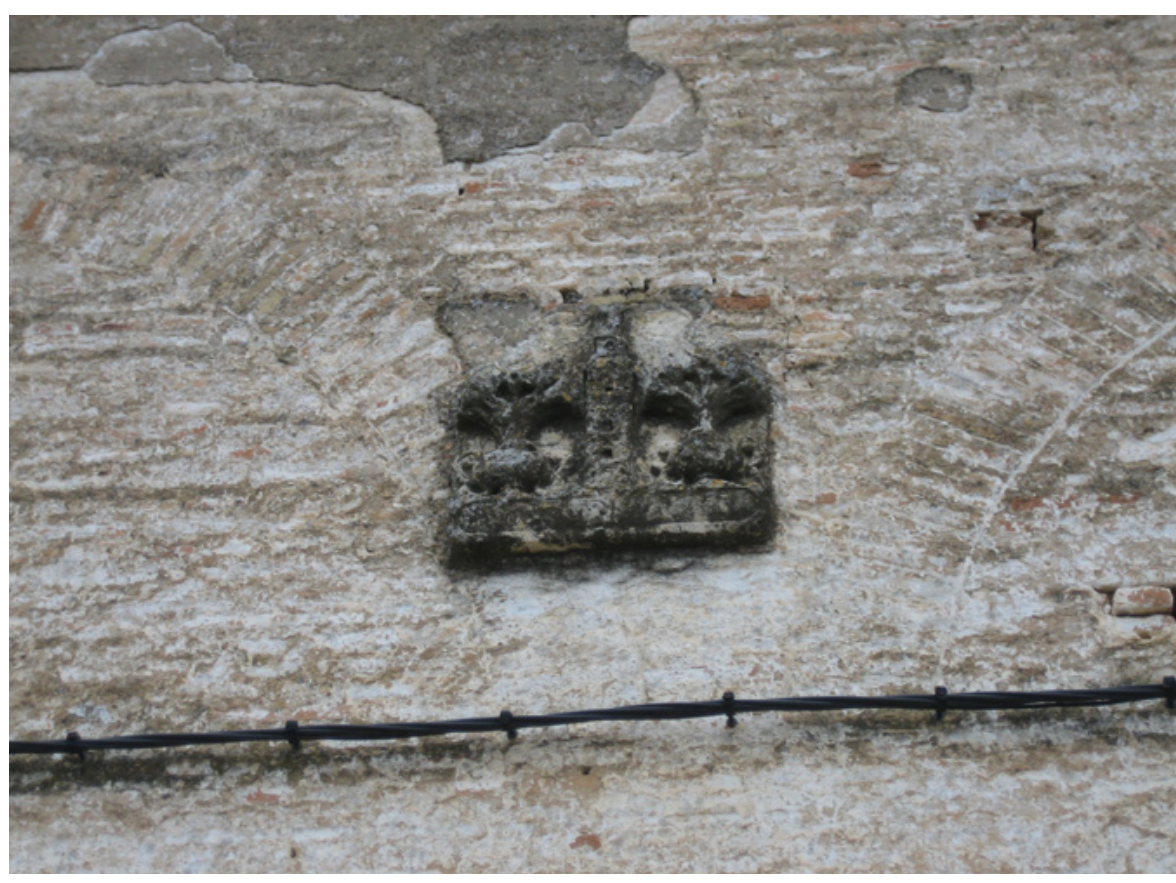

Cerámica representando la Giralda, símbolo de Sevilla, situada en la bodega del Diezmo, en Manzanilla | foto Alba Espina Boa

A principios del s. XIX, el mercado americano va dejando de tener importancia. Jerez se convierte en la marca de calidad que domina el mercado europeo, absorbiendo al Condado. El principal destino de los productos del Condado oriental y central es a partir de entonces Jerez, donde se embotellaba y se exportaba a Europa, pero ya bajo esta marca. La producción del Condado se encamina desde entonces a la cantidad, más que a la calidad.

Sólo Moguer, que además de una buena producción vinícola mantenía un puerto fluvial activo en el embarcadero del Buitrón, continúa durante el s. XIX con un comercio activo con Francia, pero no basado en vinos de calidad, sino en vinos de pasto ${ }^{2}$. A finales de este siglo, ya estaba prácticamente colmatado el puerto fluvial de Moguer, haciendo inviable la exportación de sus productos, por lo que se reduce enormemente la actividad industrial vitivinícola en esta zona. Este hecho está descrito de forma muy hermosa por el moguereño Juan Ramón Jiméne $z^{3}$ dentro de Platero y yo, en el capítulo "El Río".

Los puertos de Huelva o Sevilla se convierten durante el s. XIX en las únicas vías de salida de los productos vinícolas del Condado. El vino es llevado a estos puertos a través de la nueva línea de ferrocarril Huelva-Sevilla, construida en 1875. Esta línea cuenta con su estación principal en La Palma del Condado, en la mitad de su recorrido y muy bien situada dentro de la zona del Condado central, lo que provoca una explosión de su producción de vino 


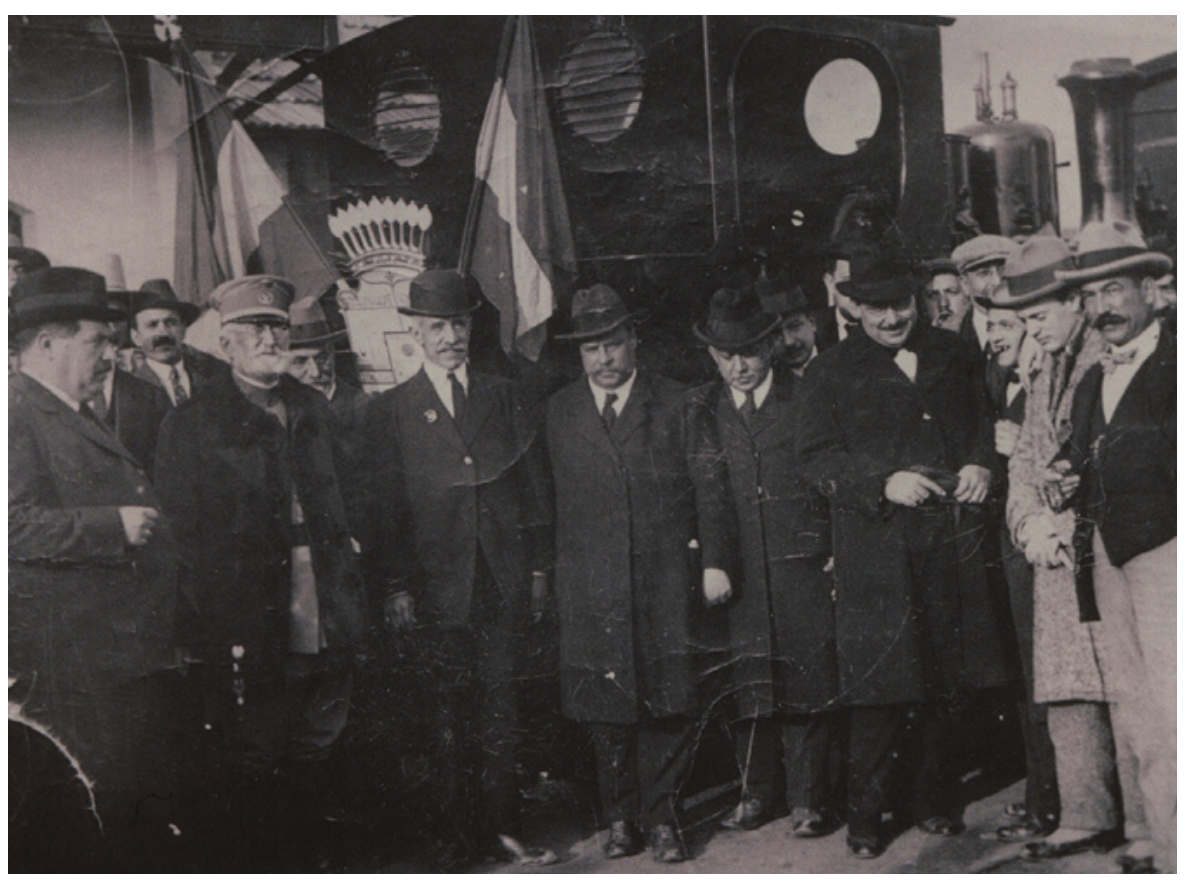

Ingenieros y personalidades en la inauguración Tren del Vino del Condado. 2 de enero de 1921 | foto Archivo Revista Corumbel, La Palma del Condado

en este periodo y la convierte desde entonces en la principal zona productora de la comarca.

En 1921 se construye "el ferrocarril del vino" (RAMíREZ CEPEDA, 2002), línea financiada por las familias vinateras de Bollullos Par del Condado para permitir llevar sus productos hasta La Palma, donde eran trasvasados a la línea Huelva-Sevilla. De esta forma se consigue conectar mediante el ferrocarril al Condado central con los puertos de Huelva y Sevilla. Este "ferrocarril del vino" estuvo activo por un corto periodo de tiempo, hasta 1931, pero su influencia contribuyó a desplazar el centro de la producción de vino desde La Palma hacia Bollullos Par del Condado 4 , el cual sigue siendo en la actualidad el municipio con mayor producción de la comarca.

Durante la primera mitad del s. XX, los viticultores de Bollullos Par del Condado, con la ayuda del Sindicato Agrícola Católico (RUIZ SÁNCHEZ, 1994), se convierten prácticamente en los únicos propietarios de la tierra, gracias a la compra común y posterior parcelación de las dehesas de Montañina y Renuñana. En 1955 (MATEO LAGARES, 2005) estos viticultores bollulleros fundan la bodega cooperativa Vinícola del Condado, la cual por producción y número de socios sigue siendo la mayor de la zona. La estrategia de asociarse en cooperativas (CARRASCO CARRASCO, 1995) para controlar el proceso del vino al completo es común en casi todos los municipios de la comarca y ha permitido mantener viva y ren-
4

Según fuentes del Consejo Regulador de Vinos del Condado, en 2014 de las 34 bodegas inscritas, 13 estaban situadas en Bollullos Par del Condado. 

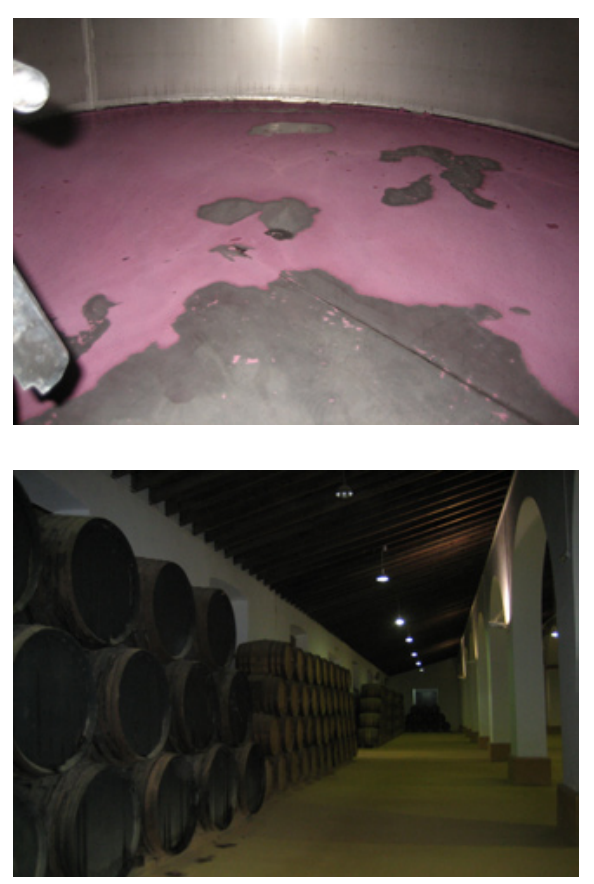

Fermentación de mosto dentro de un cono en la bodega cooperativa Vinícola del Condado, Bollullos Par del Condado

Nave principal de la bodega cooperativa Vinícola del Condado, Bollullos Par del Condado

Vista, desde la zona de "El Perú" en Bollullos Par del Condado, mostrando vides zalemas y la autopista A92 | fotos Alba Espina Boa

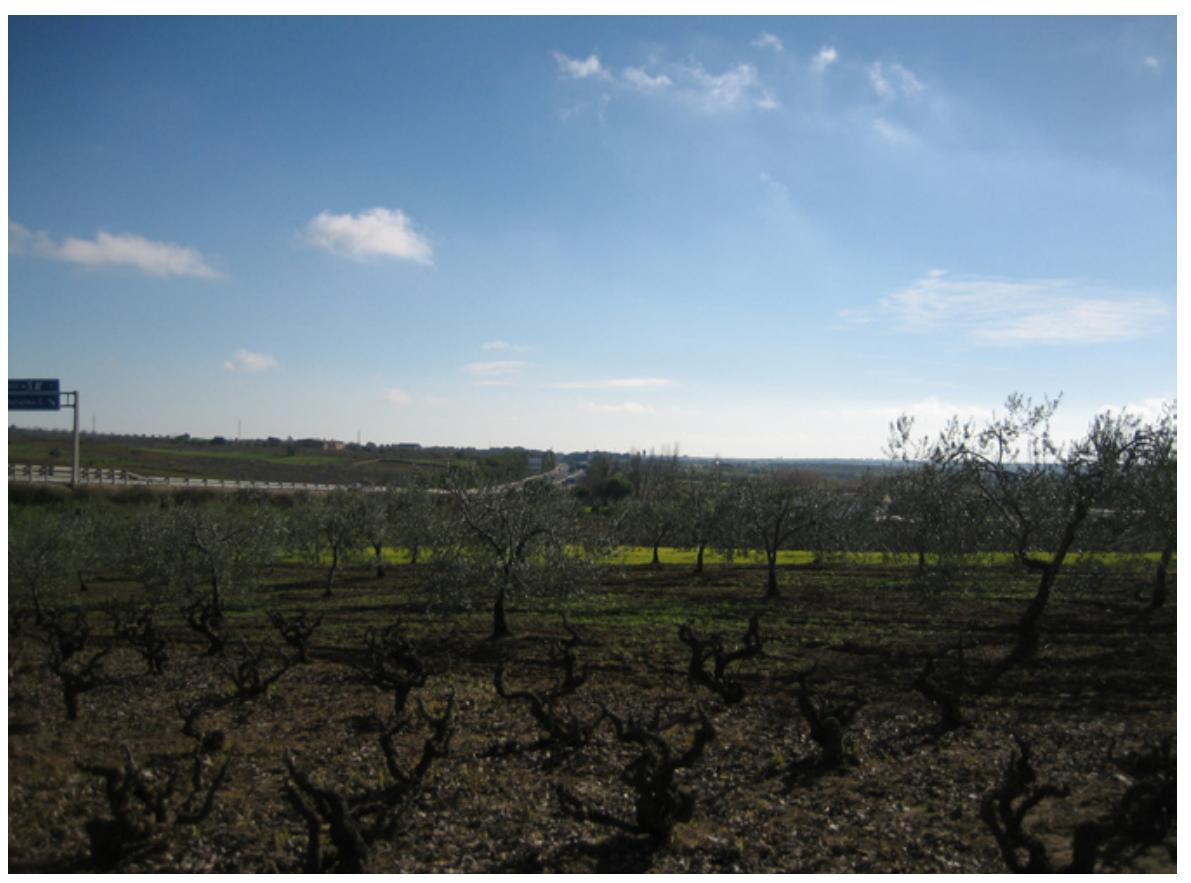

table la actividad vitivinícola en el Condado, a pesar de la crisis generalizada que sufre sector.

Por último, en la década de 1980, la construcción de la autopista A92 HuelvaSevilla desplaza en importancia al ferrocarril y se convierte en la principal vía de transporte que en la actualidad atraviesa el Condado, a través de la cual se exporta la mayor parte del vino producido en la actualidad en la comarca. 


\section{BIBLIOGRAFÍA}

- BORREROFERNÁNDEZ, M. (1995) La viña enAndalucía durante la Baja Edad Media. En IGLESIA RODRÍGUEZ, J. (ed.) Historia y cultura del vino en Andalucía. Sevilla: Universidad de Sevilla, Secretariado de Publicaciones, 1995

- CAMPOS CARRASCO, J. M.; GÓMEZ TOSCANO, F. (2001) La tierra llana de Huelva: arqueología y evolución del paisaje. Sevilla: Junta de Andalucía, Consejería de Cultura, 2001

- CARRASCO CARRASCO, M. (1995) El cooperativismo vitivinícola en el Condado onubense: análisis estratégico y plan de reestructuración. Huelva: Universidad de Huelva, 1995

- FOURNEAU, F. (1975) Bollullos, capital del viñedo. Zoido Naranjo, Florencio (traducción). Huelva: Diputación Provincial, 1975

- IGLESIASRODRÍGUEZ,J.J.(1995)Lossiglosmodernos: el impacto de la coyuntura americana y la diversificación de los mercados. En IGLESIAS RODRÍGUEZ, J. (ed.) Historia y cultura del vino en Andalucía. Sevilla: Universidad de Sevilla, Secretariado de Publicaciones, 1995

- LAREDO QUESADA, M. Á. (1992) Niebla, de reino a Condado. Huelva: Diputación Provincial de Huelva, 1992

- MATA RUIZ, D. (1995) El vino en época prerromana en Andalucía Occidental. En CELESTINO PÉREZ, S. (ed.) Arqueología del vino. Los orígenes del vino en occidente. Jerez de la Frontera: Consejo Regulador de las denominaciones de origen Jerez-Xeres-Sherry y Manzanilla-Sanlúcar de Barrameda, 1995

- MATEO LAGARES, A. (2005) Cincuenta años de una Cooperativa. La Vinícola del Condado. Bollullos Par del Condado: Bodega Cooperativa Vinícola del Condado, 2005

- RAmíREz CePEDA, M. (2002) El ferrocarril del Vino del Condado. Huelva: Asociación de Amigos del Ferrocarril "Cuenca de Río Tinto", 2002 (Monografías Garrat)

- RUIZ SÁNCHEZ, J. L. (1994) La acción social católica en la provincia de Huelva. 1903-1922: algunas consideraciones para su estudio y comprensión. En Huelva en su historia. Volumen V. Huelva: Universidad de Huelva, 1994 